\title{
Catalytic efficiency of activated carbon functionalized with phosphorus- containing groups in 2-propanol dehydration
}

Liudmyla M. Grishchenko ${ }^{\mathrm{a} *}$, Natalia S. Novychenko ${ }^{\mathrm{b}}$, Igor P. Matushko ${ }^{\mathrm{a}}$, Alexander N. Zaderko ${ }^{\mathrm{a}}$, Galyna G. Tsapyuk ${ }^{\mathrm{a}}$, Oleksandr V. Mischanchuk ${ }^{\mathrm{c}}$, Vitaliy E. Diyuk ${ }^{\mathrm{a}}$, Vladyslav V. Lisnyak ${ }^{\mathrm{a}}$ ${ }^{a}$ Department of Chemistry, Taras Shevchenko National University of Kyiv, Volodymyrska Street, 64/13, Kyiv 01601, Ukraine

${ }^{b}$ M.G. Kholodny Institute of Botany of the National Academy of Sciences of Ukraine, Tereshchenkivska Street 2, Kyiv 01004, Ukraine

${ }^{c}$ Chuiko Institute of Surface Chemistry of National Academy of Sciences of Ukraine General Naumov Street 17, Kyiv 03164, Ukraine

\section{liudmyla.grishchenko@gmail.com}

Keywords: activated carbon, surface modification, acidic groups, heterogeneous catalysts, isopropyl alcohol dehydration.

The functionalization of activated carbon (AC) by P-containing groups was conducted, and their thermal desorption was studied. Depending on the used method, the functionalized AC contains $0.5-1.45 \mathrm{mmol} / \mathrm{g}$ of acidic groups acting in catalytic 2-propanol dehydration. All catalysts showed $100 \%$ conversion of 2-propanol to propylene. The catalytic activity does not change with time under isothermal conditions and during their repeated use in catalysis, for 3 cycles of heatingcooling. In fact, the yield of propylene remains stable; it does not decrease with each cycle. Preliminary oxidation with nitric acid causes a small increase in the catalytic activity.

\section{Introduction}

Mineral strong acids are very important for chemical technology. Acid catalysis has always been developed in recent decades. As known, acidic catalysis can be driven by (i) homogeneous and (ii) heterogeneous catalysts. Liquid strong acids are often used to catalyze reactions at rather low temperatures in the homogeneous industrial catalysis. But, there are many problems with their practical adaptation. These include the formation of large amounts of wastes and the corrosive destruction of metal equipment. In fact, such an industrial process is required the laborious separation of the mineral acid catalyst from reaction products. Finally, the sequential implementation of the stages of the chemical process is necessary. On this background, the use of solid acid catalysts based on activated carbon (AC) and related solid acid materials are becoming increasingly popular and developing. 
Precursors of AC can be broad materials containing carbon in the form of natural organic compounds. The most commonly used natural precursors are agricultural wastes, wood, and natural coals [1-3]. Because of the growing demand for $\mathrm{AC}$ and increased restrictions on environmental protection, new precursors and new technologies for the production of carbons are constantly being sought. From this point of view, the use of post-agricultural and postproduction wastes has great economic and environmental advantages. Actually, AC derived from these inexpensive wastes [4] has excellent characteristics to be used as a catalyst carrier. It has a large specific surface area, regulated surface chemistry, and high chemical stability [4-7]. To increase the surface acidity, ACs can be subjected to various additional oxidative treatments. They can generate different surface groups, e.g. acidic carboxylic groups. However, these groups have low thermal stability and decompose at $250{ }^{\circ} \mathrm{C}$ [8]. Sulfonation with sulfuric acid results in an insufficient concentration of sulfogroups groups having moderate thermal stability. This does not satisfy the requirement for the effective passage of many catalytic reactions [9]. Corrosion and oxidation are degraded the carbon texture and dropped mechanical characteristics resulting in loss of activity [10]. AC is usually obtained by carbonizing the raw material in an inert atmosphere. To an increase in the adsorption capacity of the materials obtained, carbonized mass is subjected to chemical and physical activation. Phosphoric acid and related compounds containing phosphorus are used as chemical activators [11]. By adding phosphorus compounds, the mechanical and adsorption properties of carbon materials can be improved [12]. However, this activation is corrosive, and the resulted phosphorylated $\mathrm{AC}$ has limited application. Factually, the porous structure and the number of acidic sites could not be controlled after carbonation [13-16].

In this work, we functionalized AC having advanced textural parameters with phosphoruscontaining functional groups and studied their thermal desorption and catalytic activity in the dehydration of 2-propanol alcohol.

\section{Experimental part}

\section{Material and methods}

We used, as a starting material, AC obtained from fruit seeds which specific surface area is $1350 \mathrm{~cm}^{3} / \mathrm{g}$, granules of $0.5-1 \mathrm{~mm}$. For the surface functionalization, two groups of treatment methods as used. The first is direct which included the direct interaction with the modifying reagent. The second is indirect which included the pretreatment of the carbon surface before the grafting of acid groups. Preliminary surface treatment was carried out by oxidation with hydrogen peroxide and nitric acid to increase the concentration of polar groups that should be used in the substitution reactions for the formation of acid sites. Alternatively, chlorination with carbon tetrachloride at heating 
was used to functionalize carbon surface with chlorine groups to be replaced by phosphoryl groups. Here we considered the influence of the pre-oxidation treatment on the physical and chemical properties of the resulted AC.

Thermal desorption studies were carried out using thermogravimetric analysis (TGA), thermoprogrammed desorption with infrared spectrometric gas products registration (TPD IR) and thermoprogrammed desorption mass spectrometry (TPD MS) [17]. The thermal analysis was carried out in the temperature range of $30-800{ }^{\circ} \mathrm{C}$, at a heating rate of 10 ${ }^{\circ} \mathrm{C} / \mathrm{min}$. When using TGA and TPD IR simultaneously, the concentration of $\mathrm{CO}$ and $\mathrm{CO}_{2}$ desorption products was determined by IR spectrometry.

The chlorine content was determined by inverse Volgard titration for $\mathrm{Cl}^{-}$using pyrolytic decomposed samples [18]. Phosphorus, tungsten, and sulfur were found by the gravimetric method [19]. The concentration of the surface acidic sites was determined by potentiometric titration (PT) [20]. For this purpose, pre-dried AC $(0.1 \mathrm{~g})$ was poured into $25 \mathrm{ml}$ of $0.1 \mathrm{~N} \mathrm{NaOH}$ solution and kept for 24 hours. This solution was titrated, and the total acidic sites concentration was calculated by the difference in $\mathrm{NaOH}$ concentrations before and after contact with the sample. The surface morphology was studied on a JEOL JSM 6060LA scanning electron microscope (SEM). Catalytic test for 2-propanol dehydration into propylene was conducted as reported earlier in $[17,21]$.

\section{Preparation}

Oxidation with nitric acid: AC (2 g) was poured into $30 \% \mathrm{HNO}_{3}(60 \mathrm{ml})$ and was refluxed on a sand bath for $2 \mathrm{~h}$. Resulted $\mathrm{AC} / \mathrm{HNO}_{3}$ was washed with distilled water to a $\mathrm{pH}$ of 5.5-6 and air-dried at $120^{\circ} \mathrm{C}$.

Oxidation with hydrogen peroxide: AC (2 g) was added to $50 \mathrm{ml}$ of $30 \% \mathrm{H}_{2} \mathrm{O}_{2}$ for $4 \mathrm{~h}$ at $25{ }^{\circ} \mathrm{C}$. Resulted $\mathrm{AC} / \mathrm{H}_{2} \mathrm{O}_{2}$ was washed with water and dried at $120^{\circ} \mathrm{C}$.

\section{Chlorination with tetrachloromethane.}

Before chlorination, decarboxylation of $\mathrm{AC}$ was carried out in dynamic argon at $500{ }^{\circ} \mathrm{C}$ for 1.5 h. At typical chlorination, AC was heated in argon diluted $\mathrm{CCl}_{4}$ vapors at the temperature of $450{ }^{\circ} \mathrm{C}$ for $1.5 \mathrm{~h}$. After the reaction, argon flow was passed through the sample for $1 \mathrm{~h}$ and then $\mathrm{AC} / \mathrm{CCl}_{4}$ was cooled to $25{ }^{\circ} \mathrm{C}$ under argon. The decarboxylation was carried out to remove groups that cannot be substituted for chlorine: carboxylic, anhydride, and a part of lactone groups. As a result of decarboxylation, the carbon surface contains hydroxyl, carbonyl, quinone and an insignificant number of lactone groups.

Phosphorylation with phosphorus oxychloride. $2 \mathrm{~g}$ of $\mathrm{AC} / \mathrm{H}_{2} \mathrm{O}_{2}$ was decarboxylated at $450{ }^{\circ} \mathrm{C}$ to remove the carboxyl and part of the lactone groups unreactive in further phosphorylation. $1.5 \mathrm{~g}$ of decarboxylated $\mathrm{AC}$ was added to $10 \mathrm{ml}$ of $\mathrm{POCl}_{3}$ and refluxed for $3 \mathrm{~h}$. This method is 
not effective and does not result in the significant grafting of phosphoryl groups according to Scheme 1 (Figure 1). According to the chemical analysis (CA), the phosphorus content in the prepared phosphorylated $\mathrm{AC}$ is insignificant, $0.11 \mathrm{mmol} / \mathrm{g}$. Since this sample contains a few acid groups, it was excluded from further studies. Previously, we showed that the sulfonated ACs containing less than 0.2-0.3 $\mathrm{mmol} / \mathrm{g}$ of S-containing groups are low or even inactive in the dehydration reaction.

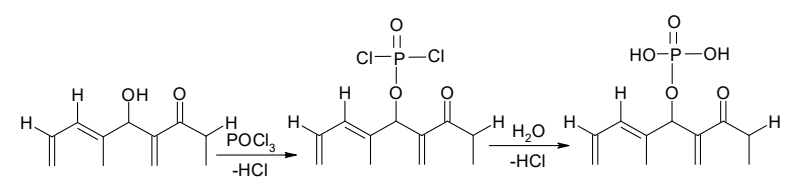

Figure 1. Scheme for functionalization of $\mathrm{AC}$ with phosphorus oxychloride.

Phosphorylation with orthophosphoric acid. Since AC phosphorylated with phosphorus oxychloride contains a few phosphoryl groups, $10 \mathrm{ml}$ of $87 \% \mathrm{H}_{3} \mathrm{PO}_{4}$ was added to $1 \mathrm{~g}$ of $\mathrm{AC} / \mathrm{CCl}_{4}$ stored in Pyrex beaker. This beaker was capped and gradually heated in an electric oven up to $350{ }^{\circ} \mathrm{C}$ for $1.5 \mathrm{~h}$, then maintained under isothermal conditions for $3 \mathrm{~h}$. In the course of the experiments, the release of $\mathrm{HCl}$ was registered as a result of the substitution reaction; see Scheme 2 (Figure 2). After cooling the sample of $\mathrm{AC} / \mathrm{CCl}_{4} / \mathrm{H}_{3} \mathrm{PO}_{4}$ was washed from unreacted $\mathrm{H}_{3} \mathrm{PO}_{4}$ with water and dried in air at $120{ }^{\circ} \mathrm{C}$. For the reaction with $\mathrm{H}_{3} \mathrm{PO}_{4}$, the initial $\mathrm{AC}$ and $\mathrm{AC} / \mathrm{H}_{2} \mathrm{O}_{2}$ were also used. Before the $\mathrm{AC}$ treatment with $\mathrm{H}_{3} \mathrm{PO}_{4}$, both them were decarboxylated at $450{ }^{\circ} \mathrm{C}$ for $2 \mathrm{~h}$ and then degassed by vacuuming for $2 \mathrm{~h}$. According to the results of CA, the phosphorus content is about $0.5 \mathrm{mmol} / \mathrm{g}$. For the pristine $\mathrm{AC}$ and oxidized AC, the content of phosphoryl groups in the resulting samples is low, far below that required for effective catalysis.

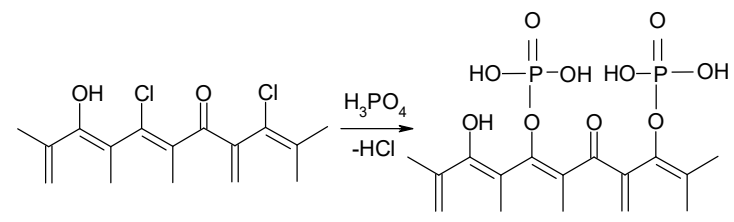

Figure 2. Scheme for $\mathrm{AC}$ functionalization with phosphoric acid.

Treatment with phosphorus tungstic acid. $1 \mathrm{~g}$ of $\mathrm{AC} \mathrm{AC} / \mathrm{H}_{2} \mathrm{O}_{2}$, and $\mathrm{AC} / \mathrm{HNO}_{3}$ was impregnated with a $5 \%(\mathrm{v} / \mathrm{v})$ water solution of $\left(\mathrm{H}_{7}\left(\mathrm{P}\left(\mathrm{W}_{2} \mathrm{O}_{7}\right)_{6} \cdot x \mathrm{H}_{2} \mathrm{O}\right)\right.$ at $100{ }^{\circ} \mathrm{C}$ for $2 \mathrm{~h}$, and then $\mathrm{AC} / \mathrm{H}_{7}\left[\mathrm{P}\left(\mathrm{W}_{2} \mathrm{O}_{7}\right)_{6}\right]$ and $\mathrm{AC} / \mathrm{X} / \mathrm{H}_{7}\left[\mathrm{P}\left(\mathrm{W}_{2} \mathrm{O}_{7}\right)_{6}\right]$ samples, where $\mathrm{X}=\mathrm{H}_{2} \mathrm{O}_{2}$ or $\mathrm{HNO}_{3}$, were dried in air at $120{ }^{\circ} \mathrm{C}$. According to the $\mathrm{CA}$, the concentration of acid sites with respect to $\mathrm{WO}_{3}$ was $1.2-1.45 \mathrm{mmol} / \mathrm{g}$.

\section{Results and discussion}

According to TPD MS, the TPD spectra of AC showed signals corresponding to $\mathrm{H}_{2} \mathrm{O}$, $\mathrm{CO}$, and $\mathrm{CO}_{2}$ desorption from the $\mathrm{AC}$ surface $(\mathrm{m} / \mathrm{z} 18,28$, and 44, respectively, Figure 3a). The water release has a wide temperature maximum at $90{ }^{\circ} \mathrm{C}$ sourced from physisorbed water. Water desorption at temperatures of 150 $350{ }^{\circ} \mathrm{C}$ occurs owing to the decomposition of carboxylic groups, which is confirmed by the simultaneous release of $\mathrm{CO}_{2}$ peaked at $250{ }^{\circ} \mathrm{C}$. Desorption of $\mathrm{H}_{2} \mathrm{O}$ at higher temperatures is due to thermal decomposition of phenolic groups, which is confirmed by significant $\mathrm{CO}$ release. 
Desorption of other fragments, including
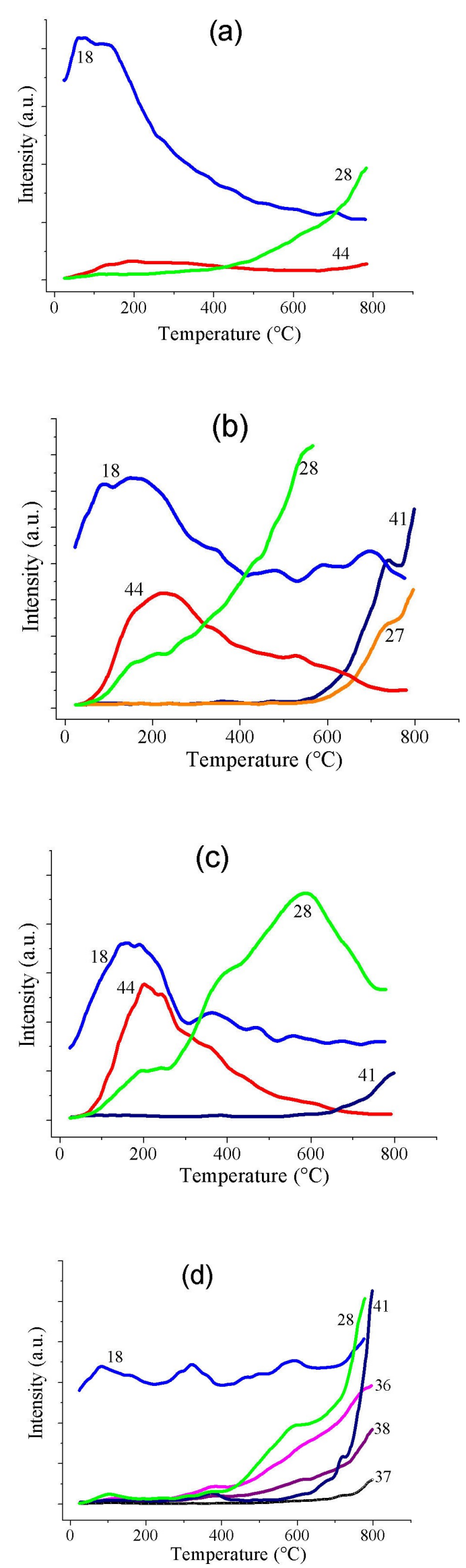

Figure 3. TPDMS profiles of (a) $\mathrm{AC}$, (b) $\mathrm{AC} / \mathrm{H}_{2} \mathrm{O}_{2}$, (c) $\mathrm{AC} / \mathrm{HNO}_{3}$, (d) $\mathrm{AC} / \mathrm{CCl}_{4}(\mathrm{~m} / \mathrm{z} \mathrm{18}, 28,41,36,37$, and $38)$. parts of the carbon matrix, don't observe in the mass spectra. The relative intensity of $\mathrm{CO}$ and $\mathrm{CO}_{2}$ release is low (Figure 3a). Only some oxygen-containing groups are present on the surface of AC. These observations are confirmed by the TGA and TPD IR data, according to which the concentration of $\mathrm{CO}$ and $\mathrm{CO}_{2}$ that formed during the thermal decomposition of oxygen-containing groups is 0.95 and $0.74 \mathrm{mmol} / \mathrm{g}$, respectively (Table 1). The total mass loss for the pristine $\mathrm{AC}$ is negligible, of about $0.06 \mathrm{~g} / \mathrm{g}$ (Figure 4a).

For $\mathrm{AC} / \mathrm{H}_{2} \mathrm{O}_{2}$ and $\mathrm{AC} / \mathrm{HNO}_{3}$, in comparison with the pristine $\mathrm{AC}$, the mass loss increases by 0.10 and $0.34 \mathrm{~g} / \mathrm{g}$, correspondingly, see Table 1. At the oxidation of AC with solutions of $\mathrm{H}_{2} \mathrm{O}_{2}$ and $\mathrm{HNO}_{3}$, there is a significant increase in the oxygen-containing groups. We registered the change in the shape and relative intensity of the profile for their thermal desorption products (Figures 3b and 3c).

Depending on the oxidant used, the functional groups are formed at a different intensity. For $\mathrm{AC} / \mathrm{H}_{2} \mathrm{O}_{2}$ and $\mathrm{AC} / \mathrm{HNO}_{3}$, the relative intensity of $\mathrm{CO}_{2}$ desorption in the entire studied temperature range, for the most between 150 and $350^{\circ} \mathrm{C}$, is significantly increasing. This fact specifies the large amounts of carboxyl groups. They are formed during the oxidative treatment. In the high-temperature region, we found intensive desorption of CO. The 
formation of phenol $\mathrm{OH}$ groups could be confirmed by this observation and hightemperature water release.

TPD MS spectra of $\mathrm{AC} / \mathrm{H}_{2} \mathrm{O}_{2}$ and $\mathrm{AC} / \mathrm{HNO}_{3}$ are in contrast to that of $\mathrm{AC}$. In addition to $\mathrm{H}_{2} \mathrm{O}, \mathrm{CO}$, and $\mathrm{CO}_{2}$ desorption, we registered a series of fragments with $\mathrm{m} / \mathrm{z} 55,42$, 41, 40, 39, 27, and 15 at above $600{ }^{\circ} \mathrm{C}$ (Figures $\mathbf{3 b}$ and $3 \mathbf{c})$. These signals are produced by hightemperature destruction of the carbon matrix. According to CA (Table 1), the oxygen content in $\mathrm{AC} / \mathrm{H}_{2} \mathrm{O}_{2}$ and $\mathrm{AC} / \mathrm{HNO}_{3}$ is increased to 4.56 and $10.6 \mathrm{mmol} / \mathrm{g}$, respectively.

Figure 3d shows TPD mass spectra of $\mathrm{AC} / \mathrm{CCl}_{4}$. The chlorination leads to less intense and nearly constant water release. Because of the decarboxylation, there is a minor $\mathrm{CO}_{2}$ emission in TPD mass spectra. But CO release is observed at above $450{ }^{\circ} \mathrm{C}$ which is the decarboxylation temperature. For $\mathrm{AC} / \mathrm{CCl}_{4}$, the content of the oxygen-containing groups remarkably drops. The concentration of oxygencontaining groups which decomposed to yield $\mathrm{CO}$ is somewhat reduced due to the decarboxylation. According to TPD IR data, we registered 2 times increase of $\mathrm{CO}$ concentration (Table 1). In our opinion, both $\mathrm{CO}-$ and $\mathrm{CO}_{2}-$ bearing sites (phenolic and lactone groups) are formed after chlorination by the mechanism of aging [22]. The concentration of chlorine, according to CA data, is $3.9 \mathrm{mmol} / \mathrm{g}$, and the mass loss increases 3 times compared to that of
AC. Chlorine desorption occurs in the form of $\mathrm{HCl}(\mathrm{m} / \mathrm{z} 36$ and 38$)$ at above $450{ }^{\circ} \mathrm{C}$.
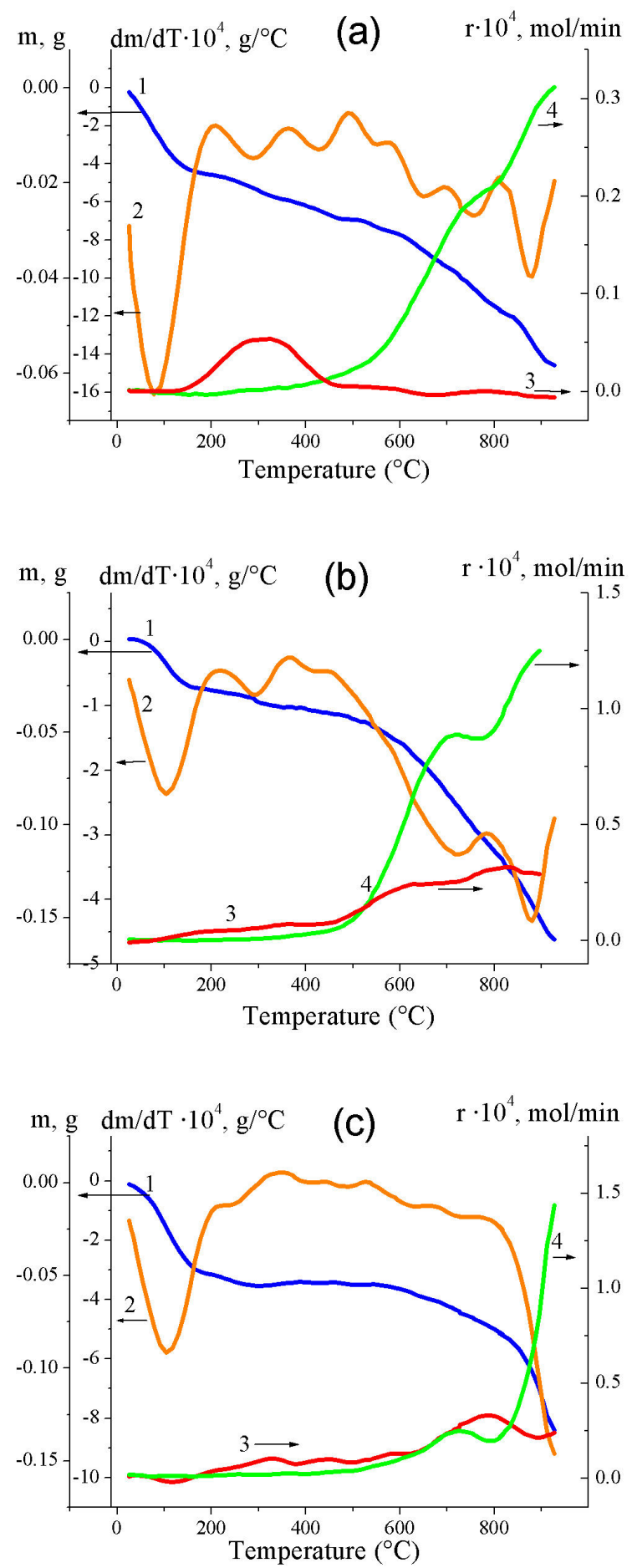

Figure 4. TGA for (a) $\mathrm{AC}$, (b) $\mathrm{AC} / \mathrm{CCl}_{4} / \mathrm{H}_{3} \mathrm{PO}_{4}$, and (c) $\mathrm{AC} / \mathrm{H}_{7}\left[\mathrm{P}\left(\mathrm{W}_{2} \mathrm{O}_{7}\right)_{6}\right]$. TG (1), DTG (2), $\mathrm{CO}_{2}$ (3) and CO (4) evolved gas rate.

For $\mathrm{AC} / \mathrm{CCl}_{4} / \mathrm{H}_{3} \mathrm{PO}_{4}$, the mass loss in the temperature range of $180-400{ }^{\circ} \mathrm{C}$ is slightly 
higher than that of the pristine AC (Figure 4b). This situation means no detectable events of the decomposition of the surface layer in this temperature range (Table 1). For this sample, the formation of small amounts of $\mathrm{CO}$ and $\mathrm{CO}_{2}$, and the absence of desorption of the latter in the region of temperatures up to $450{ }^{\circ} \mathrm{C}$ is characteristic, which is the result of preliminary decarboxylation and chlorination at $450-470{ }^{\circ} \mathrm{C}$.

Desorption of water is the only notable process occurring below $500{ }^{\circ} \mathrm{C}$ (Figure 4b). This behavior is caused, most likely, the formation of polyphosphoric acids. The main mass loss is registered at above $500{ }^{\circ} \mathrm{C}$. At the same time, we registered a significant amount of CO by TPD IR. This evolved gas is the product of thermal decomposition of carbon fragments of the matrix. It should be noted that in the mass spectra registered at below $850{ }^{\circ} \mathrm{C}$, there are no fragments that could be identified as phosphorus residues, for $\mathrm{m} / \mathrm{z}$ up to 200 . The reason for this is the formation of polyphosphoric acids. They can desorb from the carbon surface as large ions only. Consequently, one can argue that $\mathrm{AC} / \mathrm{CCl}_{4} / \mathrm{H}_{3} \mathrm{PO}_{4}$ has a substantially higher thermal stability than samples AC functionalized with sulfur-based acid sites [9]. The reason for the highest thermostability, in our opinion, is the close electronegativity of carbon and phosphorus. Consequently, phosphorous and carbon doesn't participate in redox reactions at below $800-900{ }^{\circ} \mathrm{C}$.

The treatment of the surface of AC with phosphorus-tungsten acid does not lead to significant changes in temperature dependences compared with that of $\mathrm{AC} / \mathrm{H}_{2} \mathrm{O}_{2}$ and $\mathrm{AC} / \mathrm{HNO}_{3}$. This conclusion is logical since phosphorustungsten acid (Figure 4c) does not undergo significant transformations between 30 and 850 ${ }^{\circ} \mathrm{C}$. The growth of the mass loss is observed at high temperatures, at above $600{ }^{\circ} \mathrm{C}$. It can be explained by the surface carbon oxidation with oxygen taken from $\mathrm{H}_{7}\left[\mathrm{P}\left(\mathrm{W}_{2} \mathrm{O}_{7}\right)_{6}\right]$ composition. This is confirmed by the data of mass spectrometry. In fact, the shape of the desorption peak and the temperature range of desorption of $\mathrm{H}_{2} \mathrm{O}, \mathrm{CO}$, and $\mathrm{CO}_{2}$ are in contrast to those for the pristine AC. In the former case, the amount of released desorption products is considerably larger. Another proof of the oxidizing effect of $\mathrm{H}_{7}\left[\mathrm{P}\left(\mathrm{W}_{2} \mathrm{O}_{7}\right)_{6}\right]$ is the desorption of alkane and alkene fragments $(\mathrm{m} / \mathrm{z}$ at 40, 29, 27, and 12) from the carbon matrix. We registered them at above $800{ }^{\circ} \mathrm{C}$. Similar trends are observed for oxidized carbons treated with $\mathrm{H}_{7}\left[\mathrm{P}\left(\mathrm{W}_{2} \mathrm{O}_{7}\right)_{6}\right]$. However, the hightemperature decomposition of $\mathrm{H}_{7}\left[\mathrm{P}\left(\mathrm{W}_{2} \mathrm{O}_{7}\right)_{6}\right]$ doesn't influence on catalysis, since the reaction temperature is pointedly lower. Significant mass loss observed for $\mathrm{AC} / \mathrm{H}_{2} \mathrm{O}_{2} / \mathrm{H}_{7}\left[\mathrm{P}\left(\mathrm{W}_{2} \mathrm{O}_{7}\right)_{6}\right]$ and $\mathrm{AC} / \mathrm{HNO}_{3} / \mathrm{H}_{7}\left[\mathrm{P}\left(\mathrm{W}_{2} \mathrm{O}_{7}\right)_{6}\right]$ is caused the preliminary oxidation (Table 1). According to the PT data, the total acidity ranged between 0.30 and $4.05 \mathrm{mmol} / \mathrm{g}$ of acidic groups. The main contribution to the total composition is made by the oxygen-containing groups, which 
content arises for the expanse of the preoxidation.

SEM micrographs of the surface of the pristine AC showed that there are channels of different depths and of the average size of 1030 microns in section, which are surrounded by smaller channels of 1-2 microns in section (Figure 5a). For AC samples treated with phosphoric acid and $\mathrm{H}_{7}\left[\mathrm{P}\left(\mathrm{W}_{2} \mathrm{O}_{7}\right)_{6}\right]$, the surface showed prominent changes. The channel entrances become extended. We found sufficiently long cavities which depth and porosity vary to a lesser extent for $\mathrm{AC} / \mathrm{H}_{7}\left[\mathrm{P}\left(\mathrm{W}_{2} \mathrm{O}_{7}\right)_{6}\right]$ and for the most for $\mathrm{AC} / \mathrm{CCl}_{4} / \mathrm{H}_{3} \mathrm{PO}_{4}$ (Figures 5b and 5c). For the latter, the deep channels become less porous. They disappear or, to a lesser extent, there are porous openings of deep channels. Besides, shallow channels and cavities became porous (Figure 5c).

We found a low activity of $\mathrm{AC}$ and $\mathrm{AC} / \mathrm{H}_{2} \mathrm{O}_{2}$. The yield of propylene over them is less than $25 \%$ at $300{ }^{\circ} \mathrm{C}$ (Table 1). The yield of propylene drops significantly with each cycle. In fact, $\mathrm{AC} / \mathrm{HNO}_{3}$ showed higher activity and the propylene yield. This slight increase is supplied by many carboxyl groups having a low acidity. The chlorinated $\mathrm{AC} / \mathrm{CCl}_{4}$ is inactive at all, as expected. We registered significant catalytic activity only for AC grafted with phosphoryl groups and treated with $\mathrm{H}_{7}\left[\mathrm{P}\left(\mathrm{W}_{2} \mathrm{O}_{7}\right)_{6}\right]$. For the $\mathrm{AC} / \mathrm{CCl}_{4} / \mathrm{H}_{3} \mathrm{PO}_{4}$, the temperature of the total conversion of 2propanol to propylene is $260{ }^{\circ} \mathrm{C}$. Although it is high, it maintains during heating from $25^{\circ} \mathrm{C}$ up to the temperature of the total conversion and then under respective cooling, in the heatingcooling cycle, for three times.
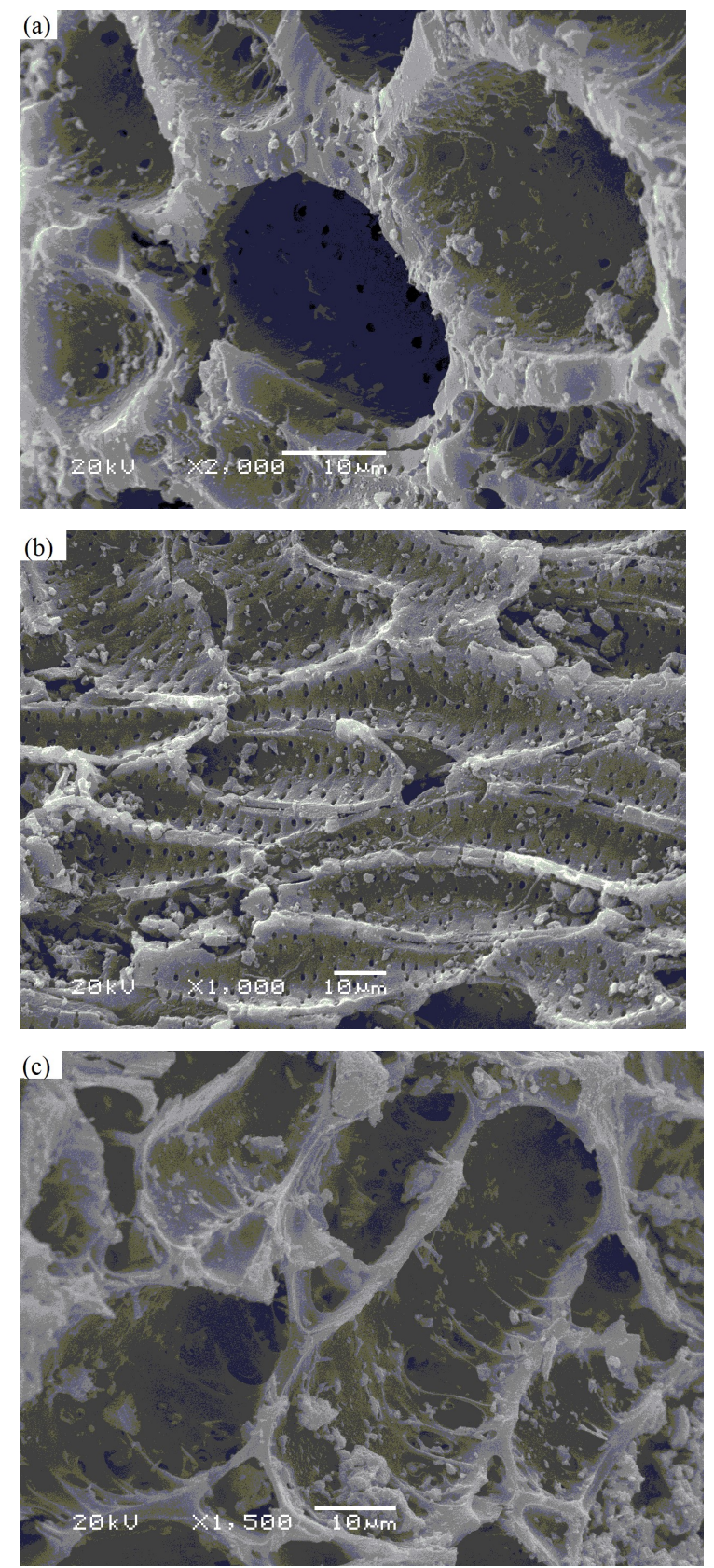

Figure 5. SEM micrographs (a) $\mathrm{AC}$, (b) $\mathrm{AC} / \mathrm{CCl}_{4} / \mathrm{H}_{3} \mathrm{PO}_{4}$, (c) $\mathrm{AC} / \mathrm{H}_{7}\left[\mathrm{P}\left(\mathrm{W}_{2} \mathrm{O}_{7}\right)_{6}\right]$. 
Table 1. Concentrations of carbon oxides $\left(C(\mathrm{CO})\right.$ and $C\left(\mathrm{CO}_{2}\right)$ from TPD IR, total acidity $\left(C_{\mathrm{PT}}\right), \mathrm{CA}$ for $\mathrm{Cl}, \mathrm{P}, \mathrm{W}$ and reaction temperature/conversion for catalytic 2-propanol dehydration for 1-3 heating-cooling cycle

\begin{tabular}{|c|c|c|c|c|c|c|c|c|}
\hline \multirow{3}{*}{$\begin{array}{c}\text { Sample } \\
\text { AC }\end{array}$} & \multicolumn{5}{|c|}{ Concentration $(\mathrm{mmol} / \mathrm{g})$} & \multicolumn{3}{|c|}{$\begin{array}{l}\text { Reaction temperature/Conversion } \\
\qquad\left({ }^{\circ} \mathrm{C} / \%\right)\end{array}$} \\
\hline & $C(\mathrm{CO})$ & $C(\mathrm{CO})$ & $C_{\mathrm{PT}}$ & \multicolumn{2}{|c|}{ CA } & 1 cycle & 2 cycle & 3 cycle \\
\hline & 0.95 & 0.74 & 0.30 & $\mathrm{O}$ & 1.37 & $300 / 25$ & $330 / 25$ & $350 / 10$ \\
\hline $\mathrm{AC} / \mathrm{H}_{2} \mathrm{O}_{2}$ & 1.87 & 1.03 & 1.47 & $\mathrm{O}$ & 4.56 & $250 / 11$ & $280 / 11$ & $300 / 8$ \\
\hline $\mathrm{AC} / \mathrm{HNO}_{3}$ & 4.29 & 4.73 & 3.77 & $\mathrm{O}$ & 10.6 & $320 / 29$ & $350 / 23$ & $350 / 15$ \\
\hline $\mathrm{AC} / \mathrm{CCl}_{4}$ & 2.1 & 0.64 & 3.9 & $\mathrm{Cl}$ & 3.9 & \multicolumn{3}{|c|}{ inactive } \\
\hline $\mathrm{AC} / \mathrm{CCl}_{4} / \mathrm{H}_{3} \mathrm{PO}_{4}$ & 3.83 & 1.54 & 0.98 & $\mathrm{P}$ & 0.5 & $260 / 100$ & $260 / 100$ & $260 / 100$ \\
\hline $\mathrm{AC} / \mathrm{H}_{7}\left[\mathrm{P}\left(\mathrm{W}_{2} \mathrm{O}_{7}\right)_{6}\right]$ & 1.61 & 1.46 & 2.25 & $\mathrm{WO}_{3}$ & 1.31 & $150 / 100$ & $150 / 100$ & $150 / 100$ \\
\hline $\mathrm{AC} / \mathrm{H}_{2} \mathrm{O}_{2} / \mathrm{H}_{7}\left[\mathrm{P}\left(\mathrm{W}_{2} \mathrm{O}_{7}\right)_{6}\right]$ & 2.38 & 1.89 & 3.03 & $\mathrm{WO}_{3}$ & 1.45 & $155 / 100$ & $155 / 100$ & $155 / 100$ \\
\hline $\mathrm{AC} / \mathrm{HNO}_{3} / \mathrm{H}_{7}\left[\mathrm{P}\left(\mathrm{W}_{2} \mathrm{O}_{7}\right)_{6}\right]$ & 3.65 & 2.52 & 4.05 & $\mathrm{WO}_{3}$ & 1.20 & $140 / 100$ & $140 / 100$ & $140 / 100$ \\
\hline
\end{tabular}

The catalyst stability in heating-cooling cycles even at relatively high temperatures showed the phosphoryl groups are grafted strongly enough to be used for industrial acid processes. The most active are $\mathrm{AC}$ treated with $\mathrm{H}_{7}\left[\mathrm{P}\left(\mathrm{W}_{2} \mathrm{O}_{7}\right)_{6}\right]$. They showed the reaction temperature at the total conversion in the range from 140 to $155{ }^{\circ} \mathrm{C}$ which is the lowest operating temperature regime. The temperatures at the total conversion do not change with repeated use of catalysts (Table 1). Preoxidation with $\mathrm{H}_{2} \mathrm{O}_{2}$ caused an increase in the temperature at the total conversion which is 5 ${ }^{\circ} \mathrm{C}$ higher for three cycles of heating-cooling. For $\mathrm{AC} / \mathrm{HNO}_{3} / \mathrm{H}_{7}\left[\mathrm{P}\left(\mathrm{W}_{2} \mathrm{O}_{7}\right)_{6}\right]$, the oxidation causes a decrease the dehydration reaction temperature by $10{ }^{\circ} \mathrm{C}$ as compared with that of $\mathrm{AC} / \mathrm{H}_{7}\left[\mathrm{P}\left(\mathrm{W}_{2} \mathrm{O}_{7}\right)_{6}\right]$. The reason for this observation could be different groups that formed on the surface of oxidized AC [23-24].

Also, we conducted additional catalytic studies to examine their activity with respect to temperature, by holding catalysts from 2 to $3 \mathrm{~h}$ under isothermal conditions. Measurements were performed at the reaction temperature that corresponds to the temperature at $50-60 \%$ isopropanol conversion. All AC-based catalysts functionalized with phosphorus-containing groups demonstrate reasonable stability of the catalytic action. They showed no events of 
deactivation within the selected time periods. Hence, the catalytic activity for other samples gradually decreases. Typically, for the most active catalysts, the temperature at the total conversion of isopropanol alcohol is far below the decomposition temperature of acid groups. Therefore, the most active catalysts exhibit higher thermal stability of phosphoryl groups. They are not subjected to thermal decomposition. No thermodesorption of $\mathrm{P}_{2} \mathrm{O}_{5}$ was observed in the reaction medium under these conditions. For other, less active catalysts, under the conditions of the dehydration reaction, at and below $300{ }^{\circ} \mathrm{C}$, the most active, acidic carboxyl groups are decomposed partially.

\section{Conclusions}

We proposed the functionalization of $\mathrm{AC}$ by phosphorus-containing functional groups with direct and indirect methods. Obtained carbon solid acids depending on the used method contain $0.5-1.45 \mathrm{mmol} / \mathrm{g}$ of acidic groups. The catalytic properties in the dehydration reaction showed that the conversion temperature depends on the total acidity and, in part, on the oxidation treatment. All phosphorylated $\mathrm{AC}$ catalysts and $\mathrm{AC}$ treated with $\mathrm{H}_{7}\left[\mathrm{P}\left(\mathrm{W}_{2} \mathrm{O}_{7}\right)_{6}\right]$ showed $100 \%$ selectivity towards propylene at the total conversion of 2propanol. The yield of propylene does not change at least 3 cycles of heating and cooling.

\section{References}

[1] Veksha A, Sasaoka E, Uddin MA. The influence of porosity and surface oxygen groups of peat- based activated carbons on benzene adsorption from dry and humid air. Carbon 2009;47:2371-2378.

[2] Wang T, Tan S, Liang C. Preparation and characterization of activated carbon from wood via microwave-induced $\mathrm{ZnCl}_{2}$ activation. Carbon 2009;47:1880-1883.

[3] Bagreev A, Menendez JA, Dukhno I and et.al. Bituminous coal-based activated carbons modified with nitrogen as adsorbents of hydro- gen sulfide. Carbon 2004;42:469-476.

[4] Bedia J, Barrionuevo R, RodriguezMirasol $\mathbf{J}$ and et.al. Ethanol dehydration to ethylene on acid carbon catalysts, Appl. Catal. B: Environ 2011;103:302-310.

[5] Dias JM, Alvim-Ferraz MCM, Almeida MF and et.al. Waste materials for activated carbon preparation and its use in aqueous-phase treatment: a review. J Environ Manag 2007;85:833-846.

[6] Dilek A. Production and characterization of activated carbon from sour cherry stones by zinc chloride. Fuel 2014;115:804-811.

[7] Kutahyali C, Eral M. Sorption studies of uranium and thorium on activated carbon prepared from olive stones: kinetic and thermodynamic aspects. J Nuclear Mat 2010;396:251-256.

[8] Bedia J, Ruiz-Rosas R, RodriguezMirasol J. and et.al. Kinetic study of the decomposition of 2-butanol on carbon-based acid catalyst. AIChE J 2010;56:1557-1568.

[9] Diyuk VE, Zaderko AN, Grishchenko LM. and et.al. Efficient carbon-based acid catalysts for the propan-2-ol dehydration. Catal. Commun 2012;27:33-37.

[10] Toda M, Takagaki A, Okamura M and et.al. Boidoisel made with sugar catalyst. Nature 2005;438(10):178.

[11] Sun J., Wu L, Wang QJ. Comparison about the structure and properties of PAN-based activated carbon hollow fibers pretreated with different compounds containing phosphorus. J Appl Polym Sci 2005;96:294300 . 
[12] Ternero-Hidalgo JJ, Rosas JM., Palomo $\mathrm{J}$ and et al. Functionalization of activated carbons by $\mathrm{HNO}_{3}$ treatment: influence of phosphorus surface groups. Carbon 2016;101:409-419.

[13] Hulicova-Jurcakova D, Puziy AM, Poddubnaya OI and et.al. Highly stable performance of supercapacitors from phosphorus-enriched carbons. JACS 2009;131:5026-5027.

[14] Bedia J, Rosas JM, Marquez J and et.al. Preparation and characterization of carbon based acid catalysts for the dehydration of 2-propanol. Carbon 2009;47:286-294.

[15] Bedia J, Rosas JM, Vera D and et.al. Isopropanol decomposition on carbon based acid and basic catalysts. Catal. Today 2010:158: 89-96.

[16] Soleimani M, Kaghazchi T. Agricultural waste conversion to activated carbon by chemical activation with phosphoric acid. Chem Eng Technol 2007;30:649-654.

[17] Multian VV, Kinzerskyi FE, Vakaliuk $\mathrm{AV}$ and et.al. Surface response of brominated carbon media on laser and thermal excitation: optical and thermal analysis study. Nanoscale Res Lett 2017;12:146.

[18] Grishchenko LM, Vakaliuk AV, Diyuk VE and etal. Functionalization of surface layer of nanoporous carbon fibers with bromine and amine functional groups. Proceedings of the 2017 IEEE 7th International Conference on Nanomaterials: Applications and Properties (NAP); 2017 Sep 10-15; Zatoka, Ukraine. P.01PCSI19-1-01PCSI19-6.

[19] Diyuk VE, Mariychuk RT, Lisnyak VV. Barothermal preparation and characterization of micromesoporous activated carbons: Textural studies, thermal destruction and evolved gas analysis with TG-TPD-IR technique. J Thermal Anal Calorim 2016;124:1119-1130.

[20] Diyuk VE, Mariychuk RT, Lisnyak VV. Functionalization of activated carbon surface with sulfonated styrene as a facile route for solid acids preparation. Mater Chem Phys 2016;184:138-145.
[21] Bezugla TM, Grishchenko LM, Vakaliuk AV and et al. Covalent bonding of sulfogroups to activated carbon fibers: The role of bromine plasma pretreatment. Mol Cryst Liq Cryst 2018;661:58-67.

[22] Diyuk VE, Gorlova AA, Grishchenko LN, Chernyavskaya TV, and Yatsimirskii VK. Kinetics of the gas-phase chlorination of activated carbon with carbon tetrachloride. Theor Exp Chem 2011; 47(4):264269.

[23] Grishchenko LM, Blyzniuk BV, Diyuk VE and et.al. Adsorption Characteristics of Nanoporous Activated Carbon Tailored with Acidic Treatment. Proceedings of the 2018 IEEE 8th International Conference on Nanomaterials: Applications and Properties (NAP). P.04NCEE10-1-04NCEE10-6.

[24] Grishchenko LM, Diyuk VE, Konoplitska OP and et.al. Modeling of copper ions adsorption onto oxidative-modified activated carbons. Adsorption Sci Technol 2017;35:884-900. 